\title{
Behaviour of iron during sediment resuspension at the glacier edge, West Antarctic Peninsula
}

\author{
RHIANNON L JONES ${ }^{1}$, AMBER ANNETT ${ }^{1}$, MAEVE \\ LOHAN $^{2}$, KORINNA KUNDE ${ }^{1}$, ALASTAIR J M LOUGH ${ }^{3}$, \\ DR. FELIPE SALES DE FREITAS, PHD ${ }^{4}$ AND JAMES \\ SCOURSE $^{5}$
}

${ }^{1}$ University of Southampton

${ }^{2}$ University of Southamtpon

${ }^{3}$ University of Leeds

${ }^{4}$ School of Earth Sciences, University of Bristol

${ }^{5}$ Exeter University

Presenting Author: rlcj1n19@soton.ac.uk

The open Southern Ocean is typically iron-limited. Hot spots of productivity are linked to fluxes of bioavailable iron downstream recirculated from shelf sediments, but the flux magnitude and longevity of this iron is poorly understood. Previous studies show both glacial meltwater events and incursions of modified Circumpolar Deep Water circulate a significant flux of iron-rich shelf material to the surface at the West Antarctic Peninsula. This incubation study investigates the short-term exchange of iron (and other trace metals) between sediments and bottom waters from three bays fed by marineterminating glaciers, distinct in hydrographic and topographic properties, at the West Antarctic Peninsula. During austral summer 2020, we collected bottom waters proximal to the ice shelf, and spiked samples with coretop sediment from the same locality. Over $48 \mathrm{~h}$ with regular mixing, we measured the concentration change of iron phases within the bottom water to assess mechanisms stabilising a sustained increase in bioavailable iron. As expected, dissolved iron concentrations ([dFe]) spiked across all experiments following sediment addition. However, the behaviour of $[\mathrm{dFe}]$ over time differs significantly between bays. Under control conditions, $[\mathrm{dFe}]$ at each bay are around $6 \mathrm{nM}$, yet the total $[\mathrm{dFe}]$ after 1 hour ranges from $89-180 \mathrm{nM}$, suggesting differing reactivity of iron-bearing minerals between bays. All incubations maintained an increase in [dFe] relative to the background level, stabilising before 48 hours. However, the contrast in the rate of decrease in [dFe], and the relative change in concentration between bays indicates a difference in stabilisation mechanisms. These mechanisms are likely caused by nanoparticulate mineral formation and complexation by organic ligands, as well as distinct bottom water oxygen levels and initial bioavailable Fe. Elevated sedimentporewater $[\mathrm{dFe}](\sim 100-500 \mu \mathrm{M})$ and evidence of significant diffusive efflux indicated by radiogenic radium measurements are also observed. Considering sustained total dissolvable iron concentrations are $>30 \mu \mathrm{M}$ for all incubations, we infer resuspended sediments as a continual significant source of iron, providing a relative increase in $\mathrm{dFe}$ compared to initial conditions. This dissolved iron may be retained in the water column long enough to provide a bioavailable flux downstream from the ice edge. 